\title{
MJN KNOWLEDGE AND PRACTICE OF FOOT CARE IN PATIENTS WITH TYPE 1 AND 2 DIABETES AT NATIONAL INSTITUTE OF DIABETES AND ENDOCRINOLOGY IN CAIRO
}

\author{
Hala Ibrahim Abo Deif *, Salwa Hagag Abdelaziz \\ Medical Surgical Nursing, Faculty of nursing, Cairo University, Egypt \\ *Corresponding Author's Email: zzhhaa77@hotmail.com
}

\begin{abstract}
Diabetes mellitus is one of the most common chronic diseases worldwide. It is one of the sixth leading causes of death in the United States. Egypt reported at least 8.6 million adults with diabetes which was the eleventh most important cause of premature mortality in Egypt. People with diabetes may develop several different foot problems as a result of nerve damage. Diabetic foot adds to economic burden due to huge expenditure on treatment, loss of productivity, frequent recurrence of the problem, and high rate of amputation. Establishing adequate knowledge and practice regarding diabetic foot care will reduce the threat of diabetic foot complications and ultimately amputation. Aim: The study determines levels of knowledge towards foot care and practices in type 1 diabetes (T1D) and type 2 diabetes (T2D). Setting: National Institute of Diabetes and Endocrinology in Cairo. Sample: About 541 patients (250 T1D and 291 T2D) was selected. Research design: Comparative descriptive exploratory design was utilized. Results: Highly significant differences were found between both groups regarding knowledge of diabetic foot care. Highly significant association was found between both groups in relation to foot care measures, no significant association between both groups as regards to levels of knowledge. A highly statistically significant association was found between the mean of knowledge scores and other variables and also with practice scores. Conclusion: Patients are aware of their disease and had desirable knowledge and poor practice of foot care. Strategies to expand a nationwide network of diabetes centers with implementation of primary prevention programs regarding foot care needed.
\end{abstract}

Keywords: Diabetes, Knowledge, Practice, Foot Care

\section{INTRODUCTION}

Diabetes mellitus (DM) is one of the most common chronic diseases worldwide. The prevalence of DM is rapidly rising all over the globe at an alarming rate. There were 415 million people estimating the incidence of $8.8 \%$ among adult aged between 20 to 79 years living with diabetes globally, 192.8 million people with diabetes were undiagnosed and $75 \%$ of them lived in low- and middle-income countries; this is estimated to rise to 642 million people by 2040 (Pagano \& Gauvreau, 2018). Every six seconds a person dies from diabetes and this makes the anticipated impact of the condition greater and more damaging in these countries than in more developed countries in the world. In Egypt, there were 7.8 million cases of diabetes among adults in 2015 and this will rise to 15.1 million cases by 2040 (Megahed et al., 2018).

Diabetes mellitus was one of the sixth leading causes of death in the United States, accounting for $3.0 \%$ of deaths each year. Similarly, diabetes was the sixth most important cause of disability burden in Egypt. It is estimated that by the year 2030, Egypt will have at least 8.6 million adults with diabetes which was the eleventh most important cause of premature mortality in Egypt, and it was responsible for $2.4 \%$ of death (Bray et al., 2018). People with diabetes are at a higher risk of developing foot problems due to elevation of blood sugar.

Diabetic foot adds to economic burden due to huge expenditure on treatment, loss of productivity, frequent recurrence of the problem, and high rate of amputation. Diabetic foot ulcers remain a major health care problem. They are common, result in considerable suffering, frequently recur, and are associated with high mortality, as well as considerable health care costs (Raghav et al., 2018). 
People with diabetes may develop a number of different foot problems as a result of nerve and blood vessel damage. These problems can easily lead to infection and ulcers which increase a persons' risk for amputation (WHO, 2009). People with diabetes carry a risk of amputation that may be more than 25 times greater than that of people without diabetes. These amputations tend to occur in patients of increasing age and those with peripheral neuropathy or chronic leg ulcers (American Diabetes Association, 2014).

Diabetes is a serious, chronic disease that impairs the body's ability to use food because either the pancreas does not make insulin, or the body cannot use insulin properly. Glucose builds up in the blood, and over many years this can cause damage to the eyes, kidneys, nerves, heart, and blood vessels. It is the leading cause of blindness, and of lower-limb amputations. Concerning mortality, adults with diabetes are at increases risk of stroke with rates of stroke and death from heart disease being 2 to 4 times higher than adults without diabetes (Ali, 2011).

Diabetic foot syndrome is one of the common and most devastating preventable complications of DM. It is associated with morbidity and premature mortality due to long-term complications affecting foot. The American Diabetes Association (2014) recommends that people with diabetes should have a comprehensive foot examination once per year. Most of the foot problems can be prevented with careful foot care. Also Chellan et al., (2012) added that practice of diabetic foot care principles including daily examination of foot and wearing appropriate footwear are essential for early detection and prevention of the expected complications. Patients with poor knowledge and practices regarding diabetic foot care have a higher incidence of foot complications including ulcers. It may take effort and time to build up good foot care habits, but self-care is essential (Taksande, Thote \& Jajoo, 2017).

The common component causes of diabetic foot ulcer formation are trauma, neuropathy and deformity. Education and awareness of diabetic foot ulcer and the existing foot care measures that are intended to control them are paramount in foot ulcer prevention strategies. Nonetheless, having knowledge of the foot care alone will not be beneficial unless practiced with good compliance. Efforts have been made to increase public awareness of diabetic foot among patients with type 1 and $2 \mathrm{DM}$ in the forms of health campaigns, public service advertisements and education by primary healthcare workers (Neville et al., 2012). Searching the literature, the investigators of the current study did not find local or international studies conducted to compare the level of knowledge and practice between type 1 and 2 DM patients towards diabetic foot care.

\section{Significance of the study}

Diabetes influence patients' physical, emotional and psychological status, leading to diseases and complications which burden patients, family and community. Achieving unmet needs through implementing appropriate care for those patients will reduce admission rates to hospital as well as the span of stay by decreasing the frequency of complications by improving patients' knowledge and practical skills. The current study will help in establishing baseline knowledge on self-care among patients with type 1 diabetes and type 2 diabetes. In this way the healthcare providers may be able to determine the gaps in the patients' knowledge and practice on foot care and provide suitable feedback. Effective educational program will be developed based on the baseline collected knowledge that can be helpful in the prevention of foot complications through proper foot care. Also establishing guidelines related to knowledge and practice by motivating health care providers to be involved in educational and caring programs for these patients. Adequate knowledge and practice regarding diabetic foot care will reduce the threat of diabetic foot complications and ultimately prevent amputation.

\begin{abstract}
Aim
The current study is conducted to determine levels of knowledge towards foot care and practices in type 1 diabetes (T1D) and type 2 diabetes (T2D) patients at National Institute of Diabetes and Endocrinology in Cairo. The aim of services provided by this institute is to meet the highest international standards in order to control diabetes, prevent and minimize its complication at an early stage.
\end{abstract}

\section{METHODOLOGY}

\section{Sample}

A convenience sample consisting of 541 patients (250 T1D and 291 T2D), representing patients accepted to participate in the current study. The study sample was calculated using power analysis of $95(\beta=1-.95=0.5)$ at alpha 0.05 (one-sided) with large effect size (0.5) was used as the significance level because this level has been suggested for use in the most areas of scientific research with confident level of $95 \%$ (Borenstein et al., 2010).

\section{Inclusion and Exclusion criteria}

The inclusion criteria are age above 20 years with T1D and T2D, both male and female. The exclusion criteria include gestational diabetes and diabetes 
insipidus. In addition, all T1D and T2D patients with diabetic foot, amputated foot, foot ulcers, impaired memory or cognitive functions along with those younger than 20 years were also excluded.

\section{Research design}

Comparative descriptive exploratory design was utilized. This research design is a mean discovering new meaning, describing what exist, determining the frequency with which something occurs and categorized information. The researcher used this type of design to find and explore the relationship between the study variables

\section{Methods}

About 541 diabetic respondents fulfilling the inclusion criteria were included in the study and recruited over the period of 18 months starting from March, 2017 to September, 2018. Demographic data sheet was developed by the researcher to collect information related to age, gender, educational level, residence and duration of diabetes. Their knowledge and practices regarding foot care were assessed by a pretested questionnaire and classified as good, desirable and poor. Eleven questions each were asked regarding knowledge and practices of foot care. This level of knowledge is divided to scores out of 33 based on the responses as correct $=3$, incorrect $=2$ and do not know $=1$.Then the score is aggregated to three levels as poor (below 19), desirable level (19-25), good level (26$33)$. The practice of foot care was assessed using questionnaire divided into score out of 22 based on the responses as yes $=2, n o=1$ and aggregated to three levels as poor (below 15), desirable level (15-18), good level (19-22). This tool was developed and modified after consulting relevant studies conducted by (MuhammadLutfi, Zaraihah \& Anuar, 2014; Desalu et al., 2011). The final version of the questionnaire related to knowledge and practice consisted of 11 items. The questionnaire was translated into Arabic language. Investigators collected information using face to face interview for 45 minutes.

\section{Validity and reliability}

Tools were reviewed by panel of three expertise in medical surgical nursing specialty, faculty of nursing and two expertise physicians in the National Institute of Diabetes and Endocrinology in order to examine the instrument for content validity and reliability, it was considered as an acceptable level.

\section{Pilot Study}

A pilot study consisted of 50 patients was done prior to the start. The study was done to ensure validity and reliability of the questionnaire and make sure that the items of the questionnaire asked to the patients were clear and understood.

\section{Data Analysis}

Data was analyzed by using SPSS version 20, Simple frequency distribution tables were generated for dependent and independent variables. Chi-square test was applied to find out whether there is any statistically significant association between socioeconomic factors and levels of knowledge and practices towards foot care in diabetic patients. Also, t-test was used to find out the significant association between demographic data, duration of diabetes and the mean score of knowledge and practice.

\section{Ethical consideration}

An official permission to conduct the study was obtained from the director of National Institute of Diabetes and Endocrinology, Cairo University. Informed consent was also obtained from the patients included in the study. The investigators of the current study explained the aim of the study and emphasizing that participation in the study is entirely voluntary and they have the right to withdraw at any time without giving any reason. Anonymity and confidentiality were assured through collecting the data.

\section{RESULTS}

Table 1 showed that the higher percentage of patients age $(48.40 \% ; 44.33 \%$ respectively in type 1 and 2) were between 41-60 years and no significant differences was found between both groups. The same tables revealed that the majority of the patients $(76 \%$ and $74.91 \%$ ) were married respectively in type 1 and 2 with no significant differences was found between both groups. Regarding educational level about one third of the patients were unable to read and write $(30.00 \%$; $31.96 \%$ ) in type 1 and 2 respectively. Also no significant differences were found between both groups in relation to gender, occupation and place of residence.

Table 2 revealed a highly significant differences between both groups regarding knowledge of diabetic foot care as the correct responses was more among T1D $(72.4 \%)$ in comparison with T2D (20.3\%) their response was correct. DM patients should look after their feet because they may not feel a minor injury to their feet. A highly significant association also was found between both groups in relation to foot care measures. Patients should look after their feet because they may get a foot ulcer: washing of the feet continuously is important and dryness of skin or fissure 
must be reported to the doctor. Of all participants only $4 \% ; 4.5 \%$ in type 1 and type 2 respectively, reported lowest incorrect response in relation to knowledge of foot care measures. The frequency of inspection inside of footwear for the presence of objects or torn lining must be performed.

Table 1: Demographic characteristics of patients with type 1 and 2 diabetes mellitus

\begin{tabular}{|c|c|c|c|c|c|c|}
\hline \multirow[t]{2}{*}{$\begin{array}{l}\text { Demographic } \\
\text { characteristics }\end{array}$} & \multicolumn{2}{|c|}{$\begin{array}{c}\text { Type } 1 \\
\text { diabetic } \\
\text { patients } \\
(n=250)\end{array}$} & \multicolumn{2}{|c|}{$\begin{array}{c}\text { Type } 2 \\
\text { diabetic } \\
\text { patients } \\
(\mathrm{n}=291)\end{array}$} & \multirow[t]{2}{*}{$\begin{array}{c}P \\
\text { value }\end{array}$} & \multirow[t]{2}{*}{$\begin{array}{c}\text { Chi } \\
\text { square }\end{array}$} \\
\hline & No. & $\%$ & No. & $\%$ & & \\
\hline \multicolumn{7}{|l|}{ Age } \\
\hline $20-40$ & 47 & 18.80 & 49 & 16.84 & \multirow[t]{3}{*}{0.34} & \multirow[t]{3}{*}{2.13} \\
\hline $41-60$ & 121 & 48.40 & 129 & 44.33 & & \\
\hline More than 60 & 82 & 32.80 & 113 & 38.83 & & \\
\hline \multicolumn{6}{|l|}{ Gender } & \\
\hline Male & 151 & 60.40 & 168 & 57.73 & \multirow[t]{2}{*}{0.52} & \multirow[t]{2}{*}{0.39} \\
\hline Female & 99 & 39.60 & 123 & 42.27 & & \\
\hline
\end{tabular}

\begin{tabular}{|c|c|c|c|c|c|c|}
\hline \multicolumn{7}{|l|}{ Marital status } \\
\hline Single & 30 & 12.00 & 34 & 11.68 & \multirow[t]{4}{*}{0.7} & \multirow[t]{4}{*}{1.38} \\
\hline Married & 190 & 76.00 & 218 & 74.91 & & \\
\hline Divorced & 17 & 6.80 & 17 & 5.85 & & \\
\hline Widow & 13 & 5.20 & 22 & 7.56 & & \\
\hline \multicolumn{7}{|l|}{ Occupation } \\
\hline Unemployed & 46 & 18.40 & 72 & 24.74 & \multirow[t]{5}{*}{0.45} & \multirow[t]{5}{*}{4.68} \\
\hline Employed & 116 & 46.40 & 132 & 45.36 & & \\
\hline Student & 24 & 9.60 & 24 & 8.25 & & \\
\hline Worker & 14 & 5.60 & 14 & 4.81 & & \\
\hline house wife & 50 & 20.00 & 49 & 16.84 & & \\
\hline \multicolumn{7}{|c|}{ Educational level } \\
\hline $\begin{array}{l}\text { Cannot read } \\
\text { and write }\end{array}$ & 75 & 30.00 & 93 & 31.96 & \multirow[t]{5}{*}{0.97} & \multirow[t]{5}{*}{0.47} \\
\hline $\begin{array}{l}\text { Can read and } \\
\text { write }\end{array}$ & 89 & 35.60 & 97 & 33.33 & & \\
\hline $\begin{array}{l}\text { Primary and } \\
\text { preparatory }\end{array}$ & 32 & 12.80 & 38 & 13.06 & & \\
\hline Secondary & 31 & 12.40 & 38 & 13.06 & & \\
\hline Higher education & 23 & 9.20 & 25 & 8.59 & & \\
\hline \multicolumn{6}{|l|}{ Residence } & \\
\hline Countryside & 110 & 44.00 & 138 & 47.42 & \multirow[t]{2}{*}{0.42} & \multirow[t]{2}{*}{0.63} \\
\hline Rban & 140 & 56.00 & 153 & 52.58 & & \\
\hline
\end{tabular}

Table 2: Difference between Type 1 and Type 2 diabetic patients regarding Diabetic foot care questionnaire assessing knowledge

\begin{tabular}{|c|c|c|c|c|c|c|c|c|c|c|c|c|c|c|}
\hline \multirow{3}{*}{$\begin{array}{l}\text { Knowledge of } \\
\text { foot care }\end{array}$} & \multicolumn{6}{|c|}{ Type 1 diabetic patients $(n=250)$} & \multicolumn{6}{|c|}{ Type 2 diabetic patients(n=291) } & \multirow{3}{*}{$\begin{array}{c}\text { Chi } \\
\text { square }\end{array}$} & \multirow[t]{3}{*}{$p$-value } \\
\hline & \multicolumn{2}{|c|}{ Correct } & \multicolumn{2}{|c|}{ In correct } & \multicolumn{2}{|c|}{ Don't Know } & \multicolumn{2}{|c|}{ Correct } & \multicolumn{2}{|c|}{ In correct } & \multicolumn{2}{|c|}{ Don't Know } & & \\
\hline & No. & $\%$ & No. & $\%$ & No. & $\%$ & No. & $\%$ & No. & $\%$ & No. & $\%$ & & \\
\hline $\begin{array}{l}\text { DM patients should take } \\
\text { medication regularly } \\
\text { because they liable to get } \\
\text { DM complication }\end{array}$ & 128 & 51.2 & 5 & 2 & 117 & 46.8 & 136 & 46.7 & 112 & 38.5 & 43 & 14.8 & 0.24 & 0.622 \\
\hline $\begin{array}{ll}\text { 2. } & \text { DM patients should look } \\
\text { after their feet because } \\
\text { they may not feel a minor } \\
\text { injury to their feet }\end{array}$ & 181 & 72.4 & 49 & 19.6 & 20 & 8 & 59 & 20.3 & 129 & 44.3 & 103 & 35.4 & 62.02 & $0.0001 *$ \\
\hline $\begin{array}{l}\text { 3. DM patients should look } \\
\text { after their feet because } \\
\text { wounds and infection may } \\
\text { not heal quickly }\end{array}$ & 157 & 62.8 & 5 & 2 & 88 & 35.2 & 61 & 21.0 & 143 & 49.1 & 87 & 29.9 & 42.28 & $0.0001 *$ \\
\hline $\begin{array}{l}\text { DM patients should look } \\
\text { after their feet because } \\
\text { they may get a foot ulcer }\end{array}$ & 159 & 63.6 & 4 & 1.6 & 87 & 34.8 & 49 & 16.8 & 155 & 53.3 & 87 & 29.9 & 58.17 & $0.0001 *$ \\
\hline $\begin{array}{l}\text { 5. DM patients should not } \\
\text { smoke because smoking } \\
\text { causes poor circulation } \\
\text { affecting the feet }\end{array}$ & 111 & 44.4 & 69 & 27.6 & 70 & 28 & 115 & 39.5 & 96 & 33.0 & 80 & 27.5 & 0.07 & 0.790 \\
\hline $\begin{array}{lll}6 . & \begin{array}{l}\text { How often you } \\
\text { inspect your feet }\end{array} & \text { should }\end{array}$ & 160 & 64 & 10 & 4 & 80 & 32 & 187 & 64.3 & 87 & 29.9 & 17 & 5.8 & 2.10 & 0.147 \\
\hline $\begin{array}{l}\text { 7. Finding redness /bleeding } \\
\text { between toes is this } \\
\text { normal finding }\end{array}$ & 114 & 45.6 & 107 & 42.8 & 29 & 11.6 & 174 & 59.8 & 92 & 31.6 & 25 & 8.6 & 12.50 & $0.0001 *$ \\
\hline $\begin{array}{ll}8 . & \text { Washing of foot } \\
\text { continuously is important }\end{array}$ & 172 & 68.8 & 67 & 26.8 & 11 & 4.4 & 84 & 28.9 & 197 & 67.7 & 10 & 3.4 & 30.25 & $0.0001 *$ \\
\hline $\begin{array}{l}\text { 9. wash of foot with warm } \\
\text { water is necessary }\end{array}$ & 150 & 60 & 75 & 30 & 25 & 10 & 57 & 19.6 & 215 & 73.9 & 19 & 6.5 & 41.78 & $0.0001 *$ \\
\hline $\begin{array}{l}\text { 10. } \begin{array}{l}\text { Dryness of skin or fissure } \\
\text { are necessary to visit a } \\
\text { doctor }\end{array}\end{array}$ & 144 & 57.6 & 19 & 7.6 & 87 & 34.8 & 225 & 77.3 & 48 & 16.5 & 18 & 6.2 & 17.78 & $0.0001 *$ \\
\hline $\begin{array}{l}\text { 11. How often do you think } \\
\text { you should inspect the } \\
\text { inside of your footwear } \\
\text { for objects or torn lining }\end{array}$ & 110 & 44 & 10 & 4 & 130 & 52 & 182 & 62.5 & 96 & 33.0 & 13 & 4.5 & 17.75 & $0.0001 *$ \\
\hline
\end{tabular}


FOOT CARE IN PATIENTS WITH TYPE 1 AND 2 DIABETES MI

Table 3: Difference between Type 1 and Type 2 diabetic patients regarding Diabetic foot care questionnaire assessing practice

\begin{tabular}{|c|c|c|c|c|c|c|c|c|c|c|}
\hline \multirow[t]{3}{*}{ Practice of foot care } & \multicolumn{4}{|c|}{ Type 1 diabetic patients $(n=250)$} & \multicolumn{4}{|c|}{ Type 2 diabetic patients $(n=291)$} & \multirow{3}{*}{$\begin{array}{l}\text { Chi } \\
\text { square }\end{array}$} & \multirow[t]{3}{*}{$p$-value } \\
\hline & \multicolumn{2}{|c|}{ Yes } & \multicolumn{2}{|c|}{ No } & \multicolumn{2}{|c|}{ Yes } & \multicolumn{2}{|c|}{ No } & & \\
\hline & No. & $\%$ & No. & $\%$ & No. & $\%$ & No. & $\%$ & & \\
\hline 1. Do you Inspect feet regularly & 137 & 54.8 & 113 & 45.2 & 158 & 54.3 & 133 & 45.7 & 1.49 & 0.221 \\
\hline 2. Do you wash feet regularly & 137 & 54.8 & 113 & 45.2 & 160 & 55.0 & 131 & 45.0 & 1.78 & 0.182 \\
\hline 3. Do you wash feet with warm water & 102 & 40.8 & 148 & 59.2 & 117 & 40.2 & 174 & 59.8 & 1.03 & 0.311 \\
\hline 4. Do you trim toenails straight across & 106 & 42.4 & 144 & 57.6 & 130 & 44.7 & 161 & 55.3 & 2.44 & 0.118 \\
\hline $\begin{array}{l}\text { 5. Do you measure your feet size when last you } \\
\text { bought footwear }\end{array}$ & 126 & 50.4 & 124 & 49.6 & 153 & 52.6 & 138 & 47.4 & 2.61 & 0.106 \\
\hline $\begin{array}{l}\text { 6. Do you received advice when last you bought } \\
\text { footwear }\end{array}$ & 125 & 50.0 & 125 & 50.0 & 147 & 50.5 & 144 & 49.5 & 1.78 & 0.182 \\
\hline 7. Did you ever inspect inside of footwear & 104 & 41.6 & 146 & 58.4 & 119 & 40.9 & 172 & 59.1 & 1.01 & 0.315 \\
\hline 8. Do you regularly walk barefoot & 87 & 34.8 & 163 & 65.2 & 91 & 31.3 & 200 & 68.7 & 0.09 & 0.764 \\
\hline 9. Do you clean nails with sharp instrument? & 91 & 36.4 & 159 & 63.6 & 105 & 36.1 & 186 & 63.9 & 1.00 & 0.317 \\
\hline $\begin{array}{l}\text { 10. Do you add irritant } \mathrm{s} \text { to water before feet } \\
\text { cleaning }\end{array}$ & 101 & 40.4 & 149 & 59.6 & 110 & 37.8 & 181 & 62.2 & 0.38 & 0.536 \\
\hline 11. Do you wear cotton stoke & 170 & 68.0 & 80 & 32.0 & 182 & 62.5 & 109 & 37.5 & 0.41 & 0.522 \\
\hline
\end{tabular}

Table 3 indicated that (68\%) of patients with T1D mentioned that, they wear cotton socks regularly while around one third of them in both groups they did not wear cotton socks. Out of the total study population, $(65.2 \% ; 68.7 \%$ among $\mathrm{T} 1 \mathrm{D}$ and $\mathrm{T} 2 \mathrm{D}$ respectively) reported that they do not walk barefooted. Certain practices were positive for example, $54.8 \% ; 54.3 \%$ respectively in T1D and T $2 \mathrm{D}$ inspect inside their feet regularly. However no significant association was found between patients both groups regarding practice with none of the variables had $P$ value of less than 0.05 .

Table 4a: Difference between Type 1 and Type 2 diabetic patients regarding levels of knowledge and practice

\begin{tabular}{|c|c|c|c|c|c|c|c|c|c|c|c|c|}
\hline \multirow[t]{3}{*}{ levels } & \multicolumn{4}{|c|}{ Knowledge } & \multirow[t]{2}{*}{ Chi square } & \multirow[t]{2}{*}{$P$ value } & \multicolumn{4}{|c|}{ Practice } & \multirow{2}{*}{$\begin{array}{c}\text { Chi } \\
\text { square }\end{array}$} & \multirow[t]{2}{*}{$P$ value } \\
\hline & \multicolumn{2}{|c|}{$\begin{array}{l}\text { Type } 1 \text { diabetic } \\
\text { patients }(\mathrm{n}=250)\end{array}$} & \multicolumn{2}{|c|}{$\begin{array}{l}\text { Type } 2 \text { diabetic } \\
\text { patients }(n=291)\end{array}$} & & & \multicolumn{2}{|c|}{$\begin{array}{l}\text { Type } 1 \text { diabetic } \\
\text { patients }(\mathrm{n}=250)\end{array}$} & \multicolumn{2}{|c|}{$\begin{array}{l}\text { Type } 2 \text { diabetic } \\
\text { patients }(\mathrm{n}=291)\end{array}$} & & \\
\hline & No. & $\%$ & No. & $\%$ & 0.21 & 0.97 & No. & $\%$ & No. & $\%$ & 1.58 & 0.45 \\
\hline Poor & 22 & 8.8 & 26 & 9.0 & & & 106 & 42.4 & 120 & 41.2 & & \\
\hline Desirable & 111 & 44.4 & 134 & 46.0 & & & 62 & 24.8 & 85 & 29.2 & & \\
\hline Good & 117 & 46.8 & 131 & 45.0 & & & 82 & 32.8 & 86 & 29.6 & & \\
\hline
\end{tabular}

Table 4b: Difference between Type 1 and Type 2 diabetic patients regarding levels of knowledge and practice

\begin{tabular}{|c|c|c|c|c|c|c|c|c|}
\hline & \multicolumn{2}{|c|}{ Knowledge } & & & \multicolumn{2}{|c|}{ Practice } & & \multirow[b]{2}{*}{$P$ value } \\
\hline & $\begin{array}{l}\text { Type } 1 \text { diabetic } \\
\text { patients }(\mathrm{n}=250)\end{array}$ & $\begin{array}{l}\text { Type } 2 \text { diabetic } \\
\text { patients }(\mathrm{n}=291)\end{array}$ & $T$-test & $P$ value & $\begin{array}{l}\text { Type } 1 \text { diabetic } \\
\text { patients }(\mathrm{n}=250)\end{array}$ & $\begin{array}{l}\text { Type } 2 \text { diabetic } \\
\text { patients }(\mathrm{n}=291)\end{array}$ & $T$-test & \\
\hline Mean & 23.8 & 23.9 & \multirow[t]{2}{*}{0.25} & \multirow[t]{2}{*}{0.79} & 16.1 & 16.09 & \multirow[t]{2}{*}{0.22} & \multirow[t]{2}{*}{0.82} \\
\hline SD & 4.05 & 4.01 & & & 4.2 & 4.1 & & \\
\hline
\end{tabular}

*significant at $P$ value $<0.05$

Table 4a showed no significant association between both groups as regards levels of knowledge $(P=0.97$, $X=0.21)$ as less than half of patients with T1D and T2D had desirable and good knowledge of foot care, the number of patients with poor knowledge was $8.8 \%$ and $9.0 \%$ in type 1 and 2 respectively. Regarding practice of diabetic foot care, the higher percentage of patients among both groups $(42.4 ; 41.2$ in type 1 and 2 respectively) had poor practice of foot care and around one third $(32.8 ; 29.6$ in type 1 and 2 respectively) had good practice. In table (4b), the mean knowledge score in type 1 and 2 was $23.8 ; 23.9$ respectively while the mean practice score was 16.1 and 16.09 in type 1 and 2 respectively. 
Table 5: Association between demographic characteristics and score of knowledge and practice

\begin{tabular}{|c|c|c|c|c|c|c|}
\hline \multirow[t]{2}{*}{ Demographic characteristics } & \multicolumn{2}{|c|}{ Knowledge score } & \multirow[t]{2}{*}{$P$ value } & \multicolumn{2}{|c|}{ Practice score } & \multirow[t]{2}{*}{$P$ value } \\
\hline & Mean & $\mathrm{SD}$ & & Mean & $\mathrm{SD}$ & \\
\hline \multicolumn{7}{|l|}{ Age } \\
\hline $20-40$ & 26.21 & 2.20 & \multirow[t]{3}{*}{$0.0001^{*}$} & 12.46 & 1.70 & \multirow[t]{3}{*}{$0.0001 *$} \\
\hline $41-60$ & 23.31 & 4.12 & & 16.42 & 4.79 & \\
\hline more than 60 & 23.62 & 4.24 & & 17.47 & 3.06 & \\
\hline \multicolumn{7}{|l|}{ Gender } \\
\hline Male & 25.65 & 2.38 & \multirow[t]{2}{*}{$0.0001^{*}$} & 14.37 & 3.31 & \multirow[t]{2}{*}{$0.0001^{*}$} \\
\hline Female & 21.50 & 4.61 & & 18.57 & 4.08 & \\
\hline \multicolumn{7}{|l|}{ Education } \\
\hline $\mathrm{C}$ annot read and write & 25.16 & 3.00 & \multirow[t]{5}{*}{$0.0001^{*}$} & 13.04 & 2.32 & \multirow[t]{5}{*}{$0.0001 *$} \\
\hline C an read and write & 25.93 & 2.32 & & 15.12 & 3.40 & \\
\hline Primary and preparatory & 20.84 & 2.93 & & 19.63 & 3.97 & \\
\hline S econdary & 22.55 & 4.80 & & 19.41 & 3.17 & \\
\hline H igher education & 18.94 & 4.68 & & 20.67 & 2.47 & \\
\hline \multicolumn{7}{|l|}{ Residence } \\
\hline Countryside & 25.35 & 3.01 & \multirow[t]{2}{*}{$0.0001 *$} & 15.09 & 3.21 & \multirow[t]{2}{*}{$0.0001 *$} \\
\hline Urban & 22.81 & 4.38 & & 16.95 & 4.71 & \\
\hline
\end{tabular}

*significant at $P$ value $<0.05$

Table 5 showed a highly statistically significant association between age group and knowledge score $(P=0.000)$ as well as the practice score $(P=0.000)$. Specifically, the highest mean of the total knowledge scores was among the age group 20-40 years; whereas the highest mean of practice score was among those aged 60 years and above. A highly statistically significant association was found between the mean of knowledge scores and other variables and also with practice scores. There are certain variables like gender, educational level and residence. Males had a slightly higher mean knowledge score than females $(P=0.000)$. Similarly, practice scores were higher among female, participants with higher level of education.

Table 6: Association between duration of diabetes and score of knowledge and practice

\begin{tabular}{|l|c|c|c|c|c|c|}
\hline \multirow{2}{*}{ Variable } & \multicolumn{2}{|c|}{ Knowledge score } & P value & \multicolumn{2}{c|}{ Practice score } & Malue \\
\cline { 2 - 7 } & Mean & SD & & \multicolumn{2}{c|}{ Mean } & 3.42 \\
\hline \multicolumn{7}{|c|}{ Duration of diabetes (years) } \\
\hline $1-10$ & 25.10 & 2.97 & $0.0001^{*}$ & 14.12 & 2.80 \\
\hline $11-20$ & 20.07 & 4.41 & & 20.49 & 2.43 \\
\hline $21-30$ & 26.43 & 2.06 & & 16.75 & 2.19 \\
\hline $31-50$
\end{tabular}

Table 6 revealed a highly statistically significant association was found between the mean of knowledge scores and duration of diabetes and also with practice scores.

\section{DISCUSSION}

This comparative descriptive study conducted to determine level of knowledge and practice of foot care 
among T1D and T2D patients. Out of 541 research subjects the higher percentage in both types were in the age group between 41 and 60 years. This finding is consistent with study conducted in Jordan and Egypt (Abu Qamar, 2014; Abdelaziz et al., 2014). Whereas another study (Jinadasa \& Jeewantha, 2011) reported that the majority of their study subjects belonged to age group between 51 and 60 years. The present study showed that the higher prevalence of T1D and T2D among males than in females in compliance with the study conducted in South Eastern Nigeria (Chris et al., 2012). Whereas, another study conducted in South India (Hawal et al., 2012) found that the gender-wise distribution of the study participants revealed most of the affected patients as females.

As we consider knowledge of foot care in this sample, eight out of eleven key principles of foot care were answered as correct by more than $51.2 \%$ in T1D and, four out of eleven principles were correct by more than $59.8 \%$ in T2D. The mean knowledge score was 23.8 in T1D and 23.9 in T2D. The results showed that patients are aware of their disease and had desirable knowledge of foot care. However, the finding of this study in relation to knowledge of diabetic foot care is similar in both groups, T2D patients had low levels of correct knowledge regarding various variables and points related to foot care. This finding is supported by Marzouk et al., (2017) who stated that poor foot care knowledge was evident among patients with T2D. Other study conducted in Malaysia by Uthman, Ullah \& Shah, (2015) highlighted a good knowledge score among diabetic patients. Incongruent with study conducted in India (Hawal et al., 2012) which mentioned that patients had poor knowledge towards diabetes. Furthermore, another study (Abu Qamar, 2014) reported that more than half of knowledge scores were within the range of 'good' among patients in the study. Since the diabetic foot care is considered simple information and can be introduced easily to T1D and T2D as basic information, so we could assume that understanding of these principles is not difficult during any time of the disease. So, improvement of knowledge among these patients can be achieved through adequate and effective counseling that could be announced by mass media with financial support from the government.

Although, no statistically significant difference exists between the knowledge score and practice score $(p=0.82)$, it was observed in the current study that the higher percentage of the patients in both groups had poor practice of foot care principles. This finding is consistent with the study conducted in Jordan (Abu Qamar, 2014) who highlighted poor commitment of patients towards practice of foot care principles. Other study conducted in Lahore (Hasanian \& Sheikh, 2009) also added that only very few patients had good practices for foot care. The current study highlighted that most respondents did not follow practices of foot care that included washing of feet with warm water, trimming of toe nails straight across, inspect inside of the footwear, regular barefoot walk, nails must be cleaned with sharp instrument and add irritants to water before feet cleaning. The most remarkable findings in both groups were that of the respondents was regarding walking barefoot $(65.2 \%$ and $68.7 \%$ in T1D and T2D respectively). This finding is similar to the study conducted in Filipino (Magbanua \& Lim-Alba, 2017). Furthermore, Isip et al., (2016) reported in a study in India and Iran that $41 \%$ and $62 \%$ of individuals with diabetes walked barefoot indoors, respectively Kumhar, Dara \& Saini, 2014; Khamseh, Vatankhah \& Baradaran, 2007).

These findings in context of negligence of foot care practice may be due to the lack of patients' awareness regarding diabetes related complications that may arise due to these poor practices. These findings should encourage healthcare providers to offer diabetes educational sessions to all patients in T1D and T2D, in collaboration with healthcare institutions to allow patients to attend the diabetes educational programs and provide awareness regarding methods of performing diabetic care. So, appropriate and thorough examination as well as suitable instructions for foot care from nurses and multidisciplinary team can affect patients' health status which is reflected later on independent selfexamination along with proper foot care.

In examining the demographic variables such as age, the study finding indicated a significant association between age and knowledge and practice score as the higher mean knowledge score found in patients from 20-40 years. This observation might be due to the fact that at young age they are more educated and aware of disease condition than older people. This finding is inconsistent with other research conducted in China (Magbanua \& Lim-Alba, 2017) which stated that no correlation was found between age and level of knowledge and practice.

Regarding gender, the current study pointed out a highly significant association between gender and knowledge score as well as practice score. The mean knowledge score is higher in male than female and vice versa in mean practice score. This finding is congruent 
with another study in Nepal conducted to determine the knowledge and practice of foot care among patients with diabetes (Shrestha et al., 2017). This study reported that male patients tend to have good knowledge and practice of foot care compared to female patients. This finding is inconsistent with research carried out by Pollock, Unwin \& Connolly, (2004) who stated that females had significant higher knowledge score than male. As regards to practice score, the present study found significant association with the high practice score in female than male as mentioned previously and this is supported with other study conducted by Goodridge, Trepman \& Embil, (2005). In this study it was found that females were more active in their self-care while males sought medical advice more for acute problems. In contradiction to this Surrati et al., (2016) found that male patients showed significantly better practices as compared to females. In relation to knowledge score of females in this study, it indicates that females are more liable to have foot problems compared to male due to lack of knowledge.

As regards to association between level of education and score of knowledge and practice, there was significant association with score of knowledge and practice. This finding is consistent with the study done in Tanzania (Chiwanga \& Njelekela, 2015). Also, the current study pointed out lack of education is significantly associated with less practice score of foot care. This finding is consistent with a previous study conducted in Nepal (Agrawaal, 2015). This may be since educated patients are able to read and easily grasps the skills and information about foot care. Also, they might be able to understand how important it is to take care of their own health compared to those who are not educated. The nurses also need to emphasize the importance of protecting diabetic patients at high risk of foot problems through enhancing better understanding of knowledge and practice related to regular self-foot examination and foot care.

In relation to association between score of knowledge and practice on duration of diabetes occurrence, respondents who had diabetes form 11-20 years were more likely to have higher practice scores. In our study patients with long duration of diabetes for more than 20 years, they were apparently less keen in practicing proper foot care and their practice score was low. So current study findings indicated that practice score was not influenced by duration of diabetes mellitus. In the same line other researchers have published similar findings (Magbanua \& Lim-Alba, 2017). In contrast to this a study done in China (Li, Yuan \& Guo et al., 2014) found that the state of practice was influenced by duration of diabetes mellitus.

\section{CONCLUSION}

This study showed that patients are aware of their disease and had desirable knowledge and poor practice of foot care. A marked gap in the practices of the diabetic patients regarding foot care will be reflected indirectly on a grim situation in the primary and secondary health care facilities. Age, gender, level of education is significantly associated with level of knowledge and practice. Repeated reminders of foot care principles is effective to improve patients' motivation, also other support schemes like health education and financial assistance is necessary. Communication between health care providers and patients can also help to improve the patients' motivation. Foot care education is the most crucial tool for preventing lower leg amputation. Thus, low cost, low technology evaluation and preventive processes are enough to substantially reduce the rates of risk. It is also essential to develop health education methods by conducting classes and distributing handouts to improve patients' knowledge and practices regarding foot care. Mass media can be utilized to transfer the health education message based on the necessity of proper self-foot care.

\section{RECOMMENDATION}

Printed and electronic media must be engaged in order to improve the public awareness of diabetes and its complications. Also, there is a need to reorient and stimulate health personnel in educating diabetics patient about self-care and the practice by themselves with appropriate foot examination when and where required. Strategies must be worked out to expand a nationwide network of diabetes centers with implementation of primary prevention programs regarding foot care.

\section{REFERENCES}

Abdelaziz, S.H., Semelawy, M.M.E., Mosa, A.F., Alammy, M.A., Mohamed, A.A.A.N., Mohamed, A.A. \& Sayed, N.M. (2017). Knowledge attitude and practice among patients with type 2 diabetes mellitus: a cross-sectional 
descriptive study. Malaysian Journal of Nursing, 9(1), pp 31-37.

Abu-Qamar, M.Z. (2014). Knowledge and practice of foot self-care among Jordanians with diabetes: an interviewbased survey study. Journal of Wound Care, 23(5), pp 247-254.

Agrawaal, K.K. (2015). Patients' Awareness about the Complications of Diabetes Mellitus and Its Correlation with the Glycemic Status. Journal of Nepal Medical Association, JNMA Journal of Nepal Medical Association, 53(200), pp 284-287.

Ali, Z.H. (2011). Health and knowledge progress among diabetic patients after implementation of a Nursing Care program based on their profile. Journal of Diabetes and Metabolism, 2(2), pages 7.

American Diabetes Association. (2014). Diagnosis and classification of diabetes mellitus. Diabetes care, 37(Supplement 1), S81-S90.

Borenstein, M., Hedges, L.V., Higgins, J.P.T. \& Rothstein, H.R. (2010). Introduction to Meta-Analysis. John Wiley \& Sons, Ltd., USA.

Bray, F., Ferlay, J., Soerjomataram, I., Siegel, R.L., Torre, L.A. \& Jemal, A. (2018). Global cancer statistics 2018: GLOBOCAN estimates of incidence and mortality worldwide for 36 cancers in 185 countries. CA: A Cancer Journal for Clinicians, 68(6), pp 394-424.

Chellan, G., Srikumar, S., Varma, A.K., Mangalanandan, T.S., Sundaram, K.R., Jayakumar, R.V., Bal, A. \& Kumar, H. (2012). Foot care practice-the key to prevent diabetic foot ulcers in India. Foot (Edinburgh, Scotland), 22(4), pp 298-302.

Chiwanga, F.C. \& Njelekela, M.A. (2015). Diabetic Foot: Prevalence, Knowledge, and Foot Self-Care Practices among Diabetic Patients in Dar es Salaam, Tanzania-ACross-Sectional Study. Journal of Foot and Ankle Research, 8: 20.

Chris, E., Ekpenyong, U., Akpan, J., Daniel, E. \& Nyebuk, K. (2012). Gender and age specific prevalence andassociated risk factors of type 2 diabetes mellitus in Uyo metropolis, south eastern Nigeria. Diabetologia Croatica, 41(1), pp 17-23.

Desalu, O.O., Salawu, F.K., Jimoh, A.K., Adekoya, A.O., Busari, O.A. \& Olokoba, A.B. (2011). Diabetic foot care: self-reported knowledge and practice among patients attending three tertiary hospital in Nigeria. Ghana Medical Journal, 45(2), pp 60-65.

Goodridge, D., Trepman, E. \& Embil, J.M. (2005). Health-related quality of life in diabetic patients with foot ulcers. The Wound, Ostomy and Continence Nurses Society, 42(1), pp 368-376.

Hasnain, S. \& Sheikh, N.H. (2009). Knowledge and practices regarding foot care in diabetic patients visiting diabetic clinic in Jinnah Hospital, Lahore. Journal of Pakistan Medical Association, 59(10), pp 687-90.

Hawal, N.P., Shivaswamy, M.S., Kambar, S., Patil, S. \& Hiremath, M.B. (2012). Knowledge, attitude and behavior regarding self-care practices among type 2 diabetes mellitus patients residing in an urban area of South India. International Multidisciplinary Research Journal, 2(12), pp 31-35.

Isip, J., de Guzman, M., Ebison, A. Jr. \& Narvacan-Montano, C. (2016). Footwear appropriateness, preferences and foot ulcer risk among adult diabetics at Makati Medical Center Outpatient Department. Journal of the ASEAN Federation of Endocrine Societies, 31(1), pp 37-43.

Jinadasa, C.V.M. \& Jeewantha, M. (2011). A study to determine the knowledge and practice of foot care in patients with chronic diabetic ulcers. International Journal of Collaborative Research on Internal Medicine \& Public Health, $3(1), \mathrm{pp} 115-122$.

Khamseh, M.E., Vatankhah, N. \& Baradaran, H.R. (2007). Knowledge and practice of foot care in Iranian people with type 2 diabetes. International Wound Journal, 4(4), pp 298-302. 
Kumhar, M., Dara, N. \& Saini, T. (2014). Foot wear and footcare knowledge - an independent risk factor for diabetic foot in Indian diabetics. Indian Medical Gazette, pp 25-28.

Li R, Yuan L, Guo X-H, Lou, Q-Q, Zhao, F., Shen, L., Zhang, M-X. \& Sun, Z-L. (2014). The current status of foot selfcare knowledge, behaviours, and analysis of influencing factors in patients with type 2 diabetes mellitus in China. International Journal of Nursing Sciences, 1(3), pp 266-271.

Magbanua, E. \& Lim-Alba, R. (2017). Knowledge and Practice of Diabetic Foot Care in Patients with Diabetes at Chinese General Hospital and Medical Center. Journal of the ASEAN Federation of Endocrine Societies, 32(2), pp $123-131$

Marzouk, D., El-Hilaly, R.A., Sos, D.G. \& Fakkar, N. (2017). Foot Care Knowledge Assessment among Type 2 Diabetic Patients attending Three Family Medicine Centers in Cairo. The Egyptian Journal of Community Medicine, 35(3), pp 43-53.

Megahed, F.I.A.E.L. (2018). Quality of life of type 2 diabetic patients attending family medicine outpatient clinic of Suez Canal university hospitals in Ismailia city thesis. Published by MedCrave Group LLC. Port Said University, Egypt.

Muhammad-Lutfi, A.R., Zaraihah, M.R. \& Anuar-Ramdhan, I.M. (2014). Knowledge and Practice of Diabetic Foot Care in an In- Patient Setting at a Tertiary Medical Center. Malaysian Orthopaedic Journal, 8(3), pp 22-26.

Neville, R.F., Capone, A., Amdur, R., Lidsky, M., Babrowicz, J. \& Sidawy, A.N. (2012). A comparison of tibial artery bypass performed with heparin-bonded expanded polytetrafluoroethylene and great saphenous vein to treat critical limb ischemia. Journal of Vascular Surgery, 56, pp 1008-1014.

Pagano, M. \& Gauvreau, K. (2018). Principles of biostatistics. $2^{\text {nd }}$ Edition. Chapman and Hall/CRC, USA.

Pollock, R.D., Unwin, N.C. \& Connolly, V. (2004). Knowledge and Practice of Foot Care in People with Diabetes. Diabetes Research and Clinical Practice, 64(2), pp 117-22.

Raghav, A., Khan, Z.A., Labala, R. K., Ahmad, J., Noor, S., \& Mishra, B.K. (2018). Financial burden of diabetic foot ulcers to world: a progressive topic to discuss always. Therapeutic advances in endocrinology and metabolism, 9(1), pp 29-31.

Shrestha, T.M., Aacharya, R.M., Shrestha, R. \& Madhav, K.C. (2017). Foot Care Knowledge and Practice among Diabetic Patients Attending General Outpatient Clinic in Tribhuvan University Teaching Hospital. Open Journal of Endocrine and Metabolic Diseases, 7(8), pp 163-171.

Surrati, A., Al-Gamdi, K., Mansuori, F. \& Al-Fahal, S. (2016). Knowledge and Practices Regarding Self-Foot Care among Diabetic Patients in Al-Madinah - KSA. Imperial Journal of Interdisciplinary Research (IJIR), 2(9), pp 1262-1265.

Taksande, B.A., Thote, M. \& Jajoo, U.N. (2017). Knowledge, attitude, and practice of foot care in patients with diabetes at central rural India. Journal of Family Medicine and Primary Care, 6(2), pp 284-287.

Uthman, M., Ullah, Z. \& Shah, N.U. (2015). Knowledge, Attitude and Practice (KAP) Survey of Type 2 Diabetes Mellitus. PJMHS, 9(1), pp 351-355.

World Health Organization (2009). Diabetes Fact Sheet, No 312. Geneva: World Health Organization. 